\title{
A Simple Tactic for Purchasing French Oak Barrels
}

\author{
Sarah Quintanar \\ University of Arkansas at Little Rock \\ Eric Sims \\ Continuum Estate \\ Sonoma State University \\ Andy Terry \\ University of Arkansas at Little Rock
}

This paper identifies a cost-minimizing tactic for U.S. wineries when buying French oak barrels. An otherwise trivial decision is potentially confounded by wineries' order timing choice and exchange rate risk. Using an intuitive model, which applies exchange rate futures prices and sixteen years of price data for a specific custom-made French oak barrel, we provide a general decision rule. The simple strategy of taking the early order discount dominates all alternative strategies and would have saved wineries nearly $\$ 78,000$ compared to the more traditional ordering timeframe. Interestingly, using futures market prices does not improve the cost savings.

"In wine, there's truth." Pliny the Elder, Natural History

Neither do men pour new wine into old wineskins. If they do, the skins will burst, the wine will spill, and the wineskins will be ruined. Instead, they pour new wine into new wineskins, and both are preserved." Matthew,9:17.

\section{INTRODUCTION}

Profit maximization and cost minimization, though straightforward in textbooks, are rendered more difficult by volatile input prices. In the wine industry, one decision is increasingly complex given exchange rate volatility and limited resources of small wineries: purchasing French oak barrels. Add the rising costs of oak barrels for reasons related to barrel production and use elsewhere and the decisions are even more involved (Stamp, 2015).

Despite acknowledging the importance of barrel purchasing decisions in operating a successful winery, little to no attention has been paid to timing of purchasing within academic or practitioner publications. ${ }^{1}$ Instead, authors have focused on storage costs, barrel type, and quality rating implications (Noparumpa, et al., 2015; Stamp, 2015). Others have explained pricing of wine through macroeconomic variables (Jiao, 2017) and the ability to predict quality and price of wine (Ashenfelter, 2008). This paper 
is the first to use data that systematically analyze the purchasing decisions pertaining to early ordering discounts ${ }^{2}$ and timing of payment for French oak barrels in euros. Wineries have the option to make barrel orders earlier than the industry norm with a discount from some suppliers, or later at full price. Determining the cost-minimizing strategy depends not only on the early order discount, but because French oak barrels are purchased in euros, the timing of the purchase and exchange rate fluctuations over time also impact the final real cost. Though some suppliers do accept payment in U.S. dollars at time of commitment, euros remain the most popular method of payment.

The present analysis approaches this cost-minimization question in a specific real-world applied framework: utilizing barrel prices paid by Robert Mondavi Winery and Continuum Estate (in Napa Valley, CA) for a specific custom-made barrel from 2001 to 2016. Since 2001, Tim Mondavi has purchased the Tarasaud Ref 102 barrel, which is considered vital to producing the high-quality red wine flavor of these wineries (Penn, 2003). ${ }^{3}$ From these prices, we extrapolate to other similar firms' decisions using exchange rate data over the same time-period and consider which ordering and payment decisions would have resulted in the lowest costs for a typical winery. In addition to the historical analysis, we consider the impact of using foreign-exchange futures prices when making the barrel purchasing decision. Adding this level of complexity does not decrease costs more than a simple decision rule.

Research within the broader context of the wine industry is not novel: questions range from understanding the impact of quality ratings on price, validity and robustness of quality ratings, as well as applying traditional economic concepts as applied to wine. For example, researchers have found expert ratings to be highly correlated with quality ratings of self-reported wine connoisseurs (Schiefer \& Fischer, 2008) and that engaging in wine futures to mitigate risk results in premiums (Noparumpa, et al., 2015). Broader scale analyses find higher quality wines have a lower exchange rate pass-through in the Argentinian wine market (Chen \& Juvenal, 2016). Relatedly, evidence exists that there is a premium to higher quality in firms' export decisions for Champagne producers (Crozet, et al., 2011).

For publicly traded companies with diversified shareholders, there are limited conditions under which it might be beneficial to hedge input/output price risk. We do not review the extensive literature here about whether firms should hedge or not, but include a few theoretical and empirical references for the interested reader. ${ }^{4}$ For family or privately-owned firms where the owners are not diversified, hedging might reduce volatility or reduce lower tail outcomes, which may be important to the owners. Our interest has less to do with the theoretical question of whether the winery should hedge, but rather with the practical question of whether futures markets or hedging could have helped reduce costs in barrel purchasing.

\section{THE WINE INDUSTRY AND FRENCH OAK}

To consider the impact of exchange rates and the early order discounts on costs, this work focuses on wineries within the United States, which produce approximately $10 \%$ of the world's wine (Wine Institute Statistics, 2015). As of July 2017, there were 9,234 wineries in the United States with the majority in California $(4,240)$, though wine production has been broadening to other states in recent years (Wines and Vines, 2017).

Though there are unlimited opinions about what makes a great wine superior, one almost universally agreed upon component of fine wine is French oak barrels, which are also expensive. For example, a single Taransaud T5 barrel was $€ 1,500$ in 2016. Despite the cost, many U.S. wineries produce fine wines and use French oak barrels in the production process. In fact, French oak barrels are the overwhelming favorite, comprising 63 percent of all new barrel purchases (Wine Business Monthly, December 2016), and 170,000 barrels are imported annually to the U.S. (personal communication with Fédération des Tonneliers de France, 2016).

Much of the complexity of purchasing barrels comes from staffing constraints at a small winery. The professional staff of a large 10,000 case winery typically includes a winemaker, viticulturist, salesperson, and accountant. These large wineries who purchase French oak barrels could employ winery accountants or controllers to develop a working knowledge of euro exchange rates and hedging strategies to be used in 
this once a year transaction. However, given the resource constraints regarding finance decisions for the more common winery, this level of staffing is impractical, and barrel decisions become a small part of an annual procedure where one employee is responsible for a wide variety of financial decisions. This paper seeks a simple and consistent tactic which could be utilized by wineries without the resources to make an independent annual decision regarding when to pay for their barrels that would minimize their costs over time.

We can look to currently operating wineries for insight into barrel needs and winery size. As of July $2017,40 \%$ of U.S. wineries were producing between 1,000 and 4,999 cases. Even more striking, 39\% were producing fewer than 1,000 cases (Wines and Vines, 2017). A high-end luxury cuvee of 1,000 cases of wine could require 40 barrels per year - assuming one hundred percent new oak. Similarly, a larger winery producing 2,500 cases of wine could require 100 new barrels per year. At $€ 929$ per Taransaud Ref 102 barrel the smaller winery would have paid $€ 37,160$ in 2016 (and, the 2,500 case winery $€ 92,900$ ). We assume a 2,500 case example for simplicity to seek a simple repeatable tactic, but can also easily be scaled in size as appropriate. ${ }^{5}$

Wineries have a few options of how to order and pay for barrels. Tonnelleries (coopers) send out order forms in January and February for standard barrel delivery in August (and September payment). All prices are denominated in euros, generally with a discount for early orders. For example, Artisan Barrels \& Tanks, Inc. 2016 Pricing Catalog states " $3 \%$ discount for all Rousseau barrels orders placed by April $1^{\text {st }}, 2016$ and delivered by June 15, 2016. Net 30 days." Another example, Bouchard Cooperages, grants a 50 euro per barrel discount (6\%) for orders placed by April 15 and delivered by July $1 .^{6}$ Though these are primarily early order discounts, the industry refers to these discounts as "early delivery" discounts. There are two important points. First, standard orders are often delivered in early August or September, shortly before the grape harvest begins. Second, the early orders may face a slightly earlier payment because the 30-day payment window follows the earlier delivery date. ${ }^{7}$

Given the individual differences in the structure of these options across coopers, we must make some simplifying assumptions, so we present costs for four basic delivery and payment options: standard order and payment; standard order and late payment; early order and early payment; and early order and prestandard payment. We also discuss the potential impact of hedging with a forward or futures contract, a practice utilized by some coopers and likely wineries as well. These options are summarized below and are organized initially by ordering timing and discount, with payment options below:

1. Standard order, receives no discount; delivery in August or September

a. Standard payment: September

b. Late payment: October

c. Hedge with a forward or futures contract

2. Order early in April and receive discount; delivery in July

d. Early payment, in April

e. Payment due in August, 30 days after early July delivery ${ }^{8}$

It should be rather obvious that ordering early with payment in August (2.e.) is likely to dominate standard order and payment in either September or October (1.a. and 1.b., respectively), as the expected exchange rate would have to fall by a larger percentage than the early order discount in just a one or twomonth time period. Thus, the significant economic comparison is between standard order and standard or late payment (1.a and 1.b., respectively) and early order and early payment (2.d.). We can model the decision as follows:

Let:

$\mathrm{P}=$ barrel price in $€$ 's

$\mathrm{d}=\%$ discount for early purchase

$\mathrm{S}=\operatorname{spot}($ April 1) $\$ / €$ exchange rate

$\mathrm{E}(\mathrm{F})=$ expected future (Sept. or Oct.) $\$ / €$ exchange rate

Then, ordering and paying for the barrel in April will cost, in dollars:

$\mathrm{P} \times(1-\mathrm{d}) \times \mathrm{S}(\$ / €)$

Similarly, ordering later and paying later will cost, in dollars: 
$\mathrm{P} \times \mathrm{E}(\mathrm{F}(\$ / €))$

Setting these two equal indicates where the winery is indifferent between the two options.

$$
\mathrm{P} \times(1-\mathrm{d}) \times \mathrm{S}(\$ / €)=\mathrm{P} \times \mathrm{E}(\mathrm{F}(\$ / €))
$$

With a little manipulation, the above can be written as:

$$
\mathrm{d}=1-\mathrm{E}(\mathrm{F}) / \mathrm{S} .^{9}
$$

and if $\mathrm{d}>1-\mathrm{E}(\mathrm{F}) / \mathrm{S} \rightarrow$ purchase now

Note that $(1-\mathrm{E}(\mathrm{F}) / \mathrm{S})$ is the expected forward discount (premium). Consequently, early purchase and payment is optimal if the early order discount, $d$, is greater than the expected forward exchange rate discount. Stated differently, the winery would delay purchase and payment only if the euro was expected to decline in value by more than the early pay discount.

Note that payment timing determines the exchange rate the winery will face in its transaction and thus the final cost and the strategy of cost minimization (i.e., with early order, normal payment, the winery will pay in euros at August's dollar/euro exchange rate). We do not consider any tactics or outcomes with orders after August: ordering this late is very uncommon due to harvest timing. A vital component to this analysis is that there are two impacts on total cost: taking advantage of the early order/delivery discount and exchange rate volatility at time of payment. ${ }^{10}$ We assume a $5 \%$ discount rate; a mid-range estimate for savings by ordering early.

\section{ANALYSIS}

The purpose of the current work is to address this extremely important, and yet, minimally discussed question: is there a simple tactic or rule to purchase French oak barrels and minimize costs? Given the infrequency of foreign transactions, lack of institutional knowledge, exchange rate volatility, and the high cost of French oak barrels, what would have been the most cost effective if a winery had a single tactic and pursued it for every year in our sample? Secondarily, we investigate the usefulness of exchange rate futures as a more complex addition to the simple strategy rule for wineries.

Figure 1 depicts the movement of actual per-barrel prices for the Taransaud Ref 102 barrel purchased by Continuum Estate. ${ }^{11}$ This barrel price acts as a proxy for many French oak barrels used in the United States wine industry, because prices likely move in the same direction over the period even with different types, coopers, sizes, or styles. French oak prices tend to increase over time due to harvest restriction and limits placed by the French government (for example, Adams 2016). Secondly, the dollar to euro exchange rate must be considered over time to see how the foreign currency market impacts this decision strategy. 12

Figure 2 below contains the USD/EUR exchange rate over the last sixteen years. As indicated in the figure, the exchange rate has been quite volatile, ranging from a low of around $\$ .83$ to a high of near $\$ 1.60$. As the U.S. dollar appreciates, American wineries can purchase French oak barrels for less in real terms. For example, if the exchange rate is 1.5 dollar per euro in April and in September is 1 dollar per euro, the winery would prefer to make its purchase in September because it would spend fewer real U.S. dollars for the same "price" in euros. There is uncertainty involved in this decision as well, because when making the purchase decision in April, it is unknown how the exchange rate will change over time. Generally, the dollar has become weaker as compared to the initial time period we consider, which means overall it requires more dollars to buy one euro. This compounds the costs over time because the barrel price in euros has increased as well.

As mentioned in the previous section, we consider four winery options for acquiring the barrels, including two that do not receive the early order discount: standard order, standard payment (order by August, payment in September) and standard order, late payment (order by August, payment in October). Conversely, if taking advantage of the early order discount, wineries could order by April 1 and pay immediately or pay 30 days after delivery (in our context, pay in April or August). These options are "early order early payment" and "early order pre-standard payment," respectively. 
FIGURE 1

NOMINAL BARREL PRICES, IN EUROS, FOR TARANSAUD REF 102 BARREL

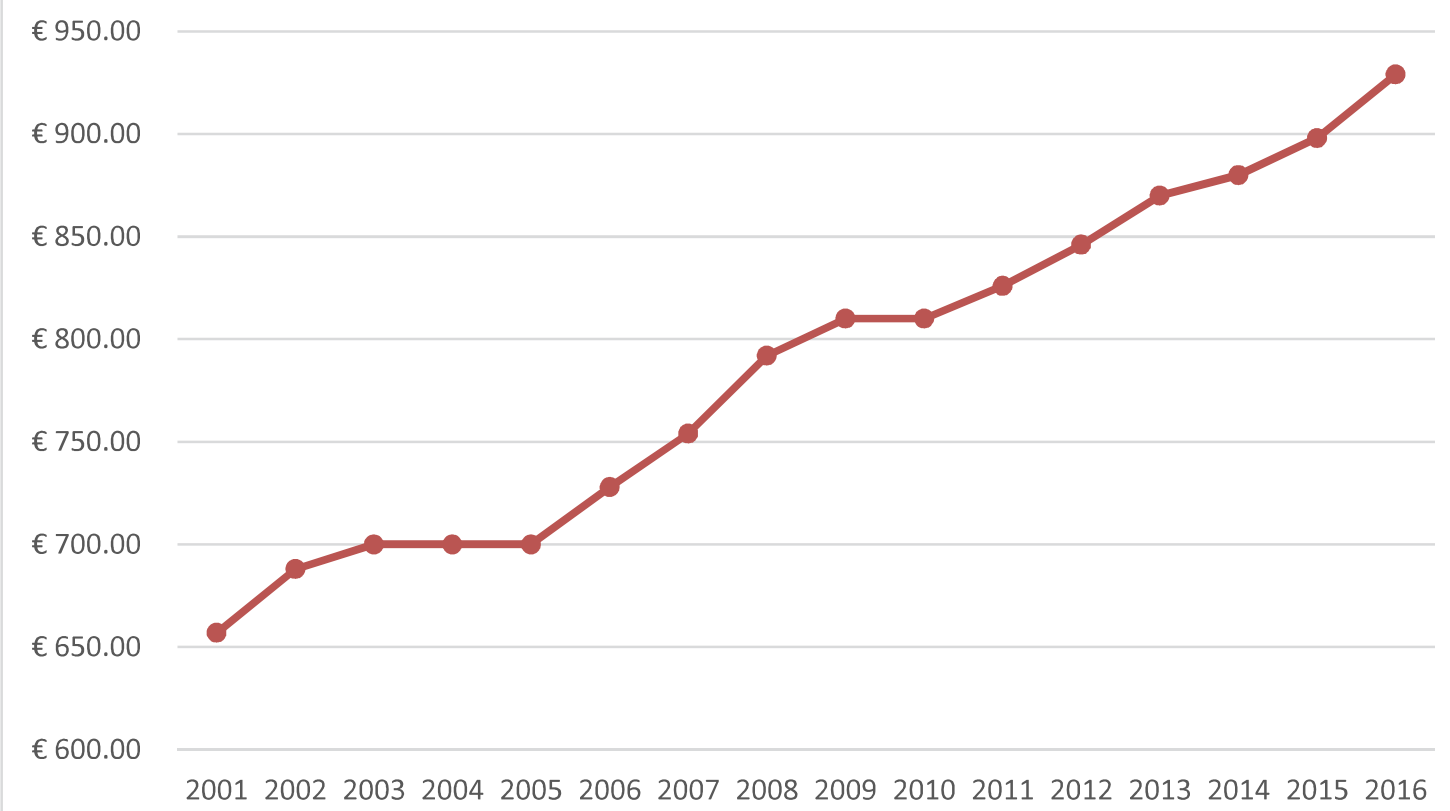

FIGURE 2

USD/EUR EXCHANGE RATE

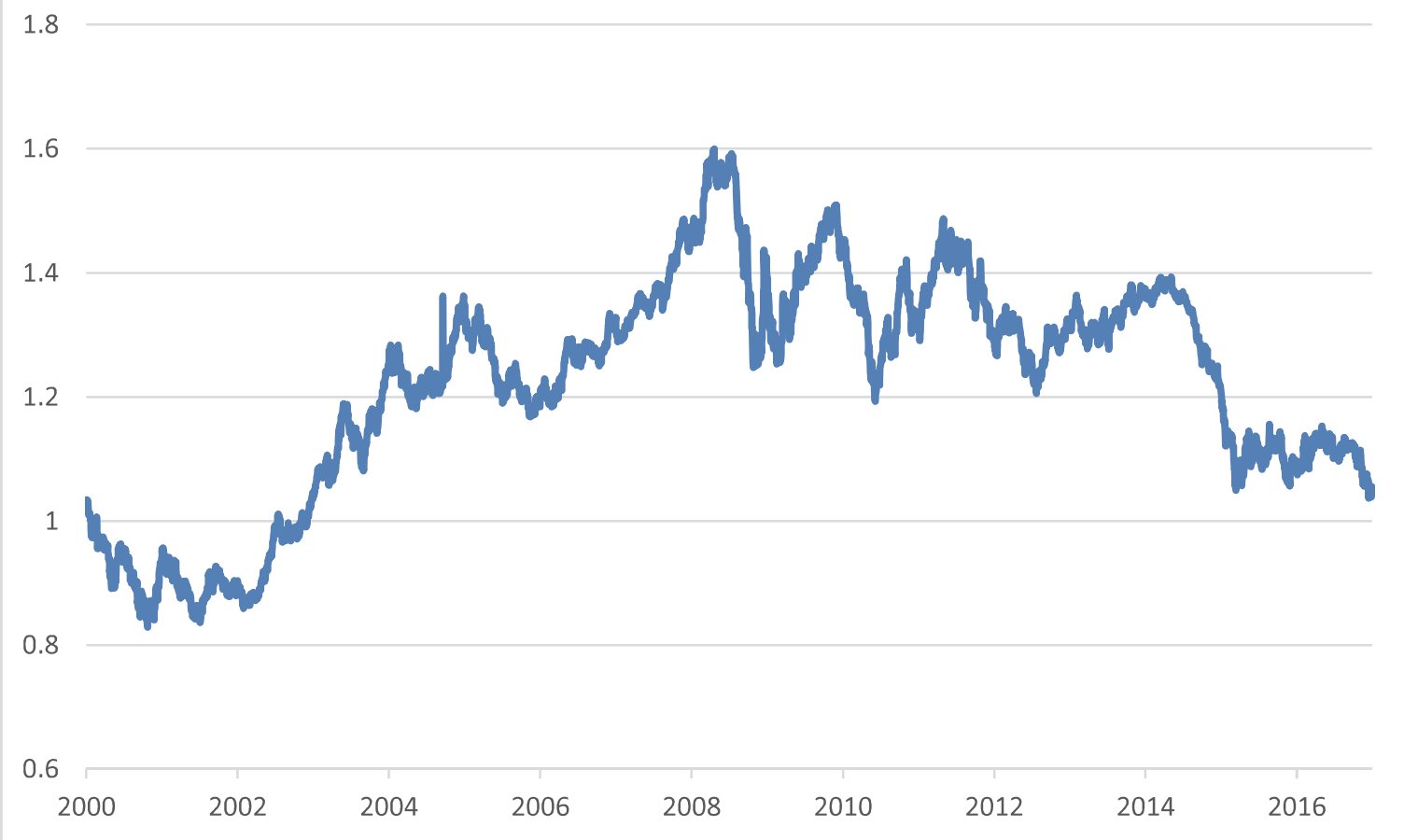


It is important to note that the price of these barrels does not change over one year: the "catalog" price and quoted discount are constant throughout a given season (year), regardless of exchange rate variation. Therefore, the financial risk the winery faces is exchange rate risk. ${ }^{13}$ If the euro significantly appreciates between the spring and the fall, then the strategy of waiting to buy the barrel could be very costly, both in terms of forgoing the discount and paying a higher exchange rate. Conversely, a significant decline in the exchange rate could make delayed purchase the better option. In discussions of purchasing, especially for the wine industry, storage costs are substantive. However, for simplicity, we do not consider additional storage costs. ${ }^{14}$

Table 1 provides calculations for the total cost of the four tactics over these sixteen years, for the hypothetical winery which purchases 100 Taransaud oak barrels at historic Continuum Estate prices. ${ }^{15}$ Figure 3 below depicts the same information in graphical form. While no single tactic is always optimal from year to year, the discounted real price in April is, on average, significantly lower than the other two options. In only three out of sixteen years was it optimal to forgo the early purchase and pay discount and wait until September or October to pay. Even when ordering and paying early was more expensive, the difference was very small. Perhaps more importantly, the variation is high for October payment: overall that choice was the most expensive.

TABLE 1

DIFFERENCE IN COST BY BARREL ORDERING AND PAYMENT DECISION



Total payment in euros for each option is presented here. The cheapest option for each year is shown in bold. We assume wineries select one consistent method of payment for the entire time period, and the savings as compared to the base payment option is presented in the first row. 


\section{FIGURE 3}

\section{FIFTEEN-YEAR HISTORY OF WINERY BARREL COSTS BY ORDER AND PAYMENT DECISIONS}

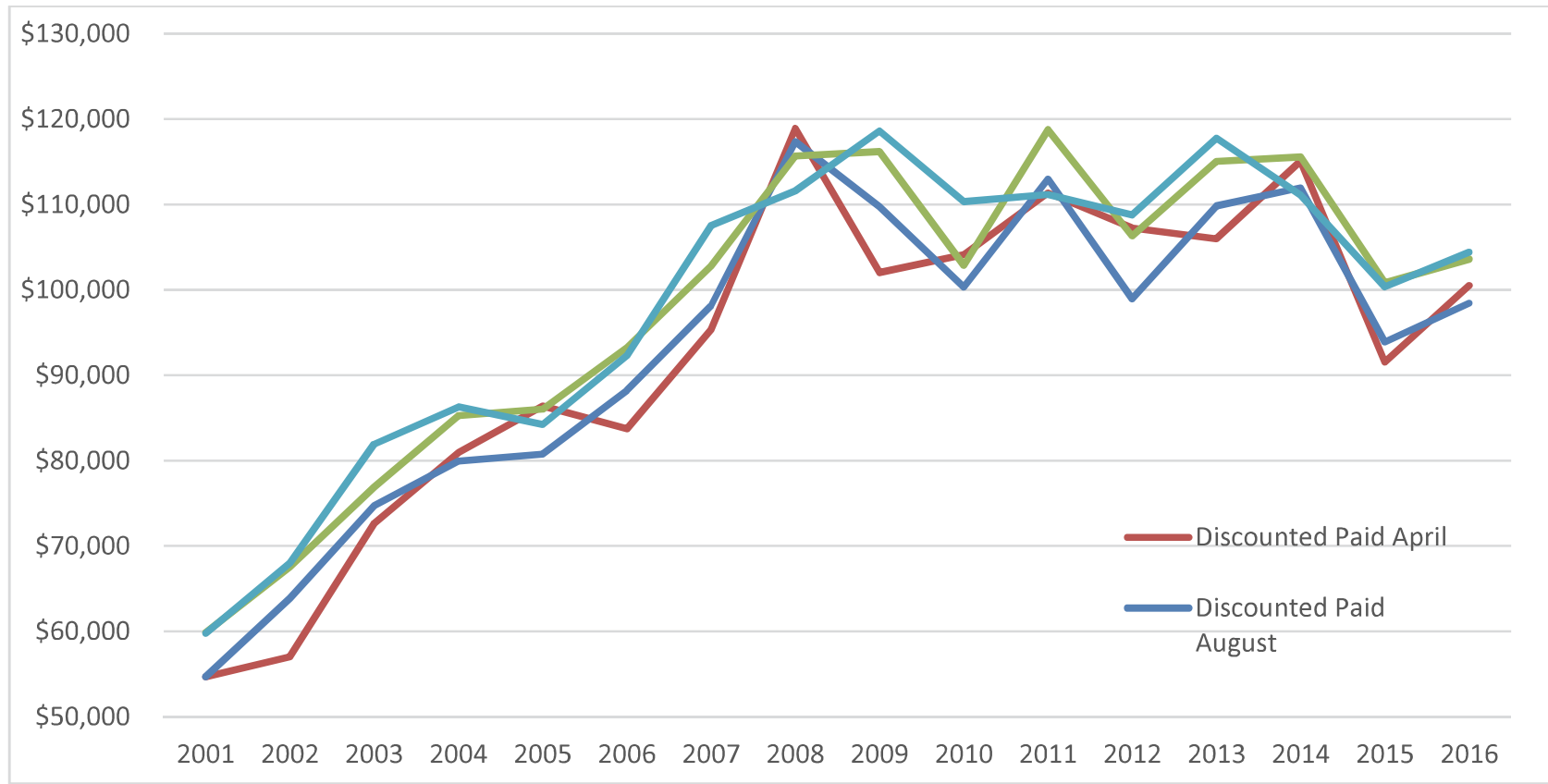

Interestingly, once exchange rate fluctuations are accounted for, there is very little difference between paying in April with the discount and paying in August with the discount. The exchange rate fluctuations do not make as big of an impact on costs as compared to the early order discount. In fact, in sixteen years of data, paying in August versus April (with the discount) would have saved the winery about six thousand dollars. In effect, after ordering early, wineries could make the decision to pay in April or August based on their own specific revenue and storage constraints without any predictable impact on cost. Space can be tight (as well as cash) in the spring and summer. The savings are significant for those wineries that make room for the next vintage barrels.

\section{FUTURES PRICES AND HEDGING}

Recall the model we employ in Section II above, which provided the simple tactic: $\mathrm{d}>1-\mathrm{F} / \mathrm{S} \rightarrow$ purchase now

Note that $(1-\mathrm{F} / \mathrm{S})$ is the forward discount (premium).

As an example, suppose the $\$ / €$ spot rate in April was 1.04 and the futures rate for September delivery was 1.00 . Then $1-1 / 1.04=3.85 \%$ and purchasing early is optimal if the discount, $\mathrm{d}$, is greater than $3.85 \%$. Note that "locking in" a forward discount would require purchasing a foreign exchange futures (or forward) contract in April, and then unwinding the contract in the fall, which requires some expertise and transaction costs. Consequently, our analysis can be used to examine the actual hedging opportunities, or to examine how information contained in futures prices might guide an optimal strategy.

As indicated in equation (1) above, early purchase and payment is optimal if the discount exceeds the expected percentage decline in the exchange rate as reflected in futures prices. We collected September euro futures prices as of the beginning of April each year and calculated the forward premium or discount implied by such prices. Focusing on only the September purchase date, using futures prices would not have improved on the simple buy early with discount strategy. ${ }^{16}$ In two of the four years where delayed 
purchase and payment was optimal, futures prices reflected a forward premium. In the other 2 years, futures prices reflected forward discounts of only $2.1 \%$ and $.11 \%$. In fact, futures prices reflected the correct direction of changes in exchange rates in only half of the sixteen years. This should not be surprising given the relatively extensive literature that indicates foreign exchange futures prices are not good predictors of future exchange rates. See, for example, Cherenko, et al., 2004 and the references contained in the literature review therein. Though in our sample the largest forward discount was only $2.1 \%$, in the event futures prices reflected a discount larger than the early payment discount, net of storage, then it still may not be optimal to delay payment because of margin requirements and futures market transaction costs.

Note also, that this model can be generalized to any industry which faces a similar structure for purchasing intermediate goods: foreign exchange rate risk and some early-order discount. All that is needed is to substitute the appropriate values into the model above.

\section{CONCLUSION}

This paper is the first systematic analysis of a cost-minimizing strategy for purchasing French oak barrels. Wineries in the United States purchase French oak barrels priced in euros and can decide to order their barrels early for an early order discount or wait and purchase later without a discount. They also have limited flexibility in the timing of payment: the most common is to pay 30 days after delivery, however they have the choice of paying early at the time they order or making late payment an additional 30 days after standard payment. Given the inherent complexities in fluctuating exchange rates and limited resources of the average winery, little consideration has been given to this purchasing decision despite potentially large monetary implications. Based on the last sixteen years, an average U.S. winery buying French oak barrels would have saved a total of nearly $\$ 80,000$ by following the simple strategy of purchasing and paying early to take advantage of the early-order discount. Further, the wineries could not have improved on this simple strategy by employing information contained in euro futures prices.

There are other benefits to early ordering besides those related to costs. Demand for high-quality wine barrels far exceeds supply. French oak forests and tree falling permits are limited and the three to five year drying process disconnects current supply and demand. On top of growing fine wine demand there are now many more uses for American oak aging like whiskey, small-batch bourbon, vodka, gin, and beer (Adamian, 2016) which will, in turn, increase demand for French oak as the price of American oak rises. Early ordering assures the winery of getting the barrels they want, and decreases the uncertainty about future shortages.

Continuum Estate in Napa is a high-end example of a California winery, though its barrel choice and production decisions can easily be extended to other similar wineries in the United States and beyond. Future work will explore whether the production risk is sufficient to justify delaying the purchase decision and foregoing the early order discount, and the external validity of these choices more broadly to lower quality commercial wineries as well. 


\section{ENDNOTES}

1. Two of the authors have a significantly simplified version of this paper containing no modeling and more limited delivery choices in the October 2017 issue of Wines \& Vines.

2. The wine industry refers to these discounts as "early delivery discounts," but given the lack of familiarity with that term for the average economist, we use the term "early order discount" because the discount is really a function of early order.

3. A bottle of Continuum sells for over $\$ 200$.

4. For examples see: Brown, 2001, Myers, 1977, Smith \& Stulz, 1985, Nance, et al., 1993, Stulz, 1984, 2013, and Journal of Applied Corporate Finance, Winter 2015 issue.

5. For example, if applying the costs estimates to a winery purchasing 40 new barrels, merely multiply the costs presented here by .40

6. Our assumptions for cost calculations are based on this timeline for delivery and payment.

7. It is possible that delivery occurs at the same time as later, more "standard" orders. This is actually a simplifying assumption which is easy to apply to our estimates since the only difference then becomes the discount itself.

8. Note we are oversimplifying to some extent especially given small differences across coopers' policies. Thirty days after delivery for early orders may fall in July, and wineries could also choose to pay immediately upon delivery in June or July. After discussions with coopers, those who offer discounts believe most early deliveries occur in July with payment in August so those are the estimates we present here. Results are no different if we assumed payment in September or July.

9. If there are storage costs associated with receiving the barrels early of $s \%$, the expression becomes: $d-s x$ $(1-d)=1-E(F) / S$. In this case, early purchase is desirable if the discount, less the after-discount cost of storage, exceeds the expected percentage decrease in the price of the Euro.

10. Some barrel producers also offer the option of a mixed strategy which includes some proportion of purchasing now and some later. In the interest of brevity the current paper does not consider the implications of this mixed strategy.

11. Provided through personal communication with Taransaud's broker in the United States.

12. Note that Chen and Juvenal (2016) find that higher priced (and quality) wines have lower pass-through. This is relevant insofar as future sales price impacts a winery's decision about whether and how many barrels to purchase and if those results correspond to barrels themselves.

13. One other risk which may motivate early ordering is the risk of the cooper "selling out" of a specific barrel.

14. Because we are considering storage of empty barrels, costs should not be nearly as significant as storage costs for barrels of wine, which have been studied in other settings (Stamp 2015).

15. This number will vary from winery to winery, but 100 provides estimates that mirror cooperage needs of a relatively small winery which is likely too small to hire a CFO or controller with the specific responsibility or skill set to hedge.

16. We also examined the October payment date. October futures are not available, so we both averaged the September and December futures and used the December futures only, and found results both qualitatively and quantitatively similar to the September results. 


\section{REFERENCES}

Adamian, J. (2016). Barrel Aging Is So Hot Right Now (Too Bad There Aren't Enough Barrels). Modern Farmer.

Adams, A. (December 2016). Oak Prices Poised for Increase. Wines \& Vines [Accessed June 2017], Available at:

https://www.winesandvines.com/sections/printout_article.cfm?article $=$ feature \&content $=177195$

Anon., n.d. About the United States Wine and Grape Industry: General Industry Stats 2014. [Online] Available at: http://wineamerica.org/policy/by-the-numbers [Accessed 26 September 2016].

Ashenfelter, O., 2008. Predicting the Quality and Prices of Bordeaux Wine. The Economic Journal, $118(529)$.

Chen, N. \& Juvenal, L., 2016. Quality, trade, and exchange rate pass-through. Journal of International Economics.

Crozet, M., Head, K. \& Mayer, T., 2011. Quality sorting and trade: Firm-level evidence for French wine. The Review of Economic Studies, November.

Gale, I. L. \& Holmes, T. J., 1993. Advance-Purchase Discounts and Monopoly Allocation of Capacity. The American Economic Review, March, 83(1), pp. 135-146.

Jiao, L., 2017. Macroeconomic Determinants of Wine Prices. International Journal of Wine Business Research, 29(3), pp. 234-250.

Noparumpa, T., Kazaz, B. \& Webster, S., 2015. Wine Futures and Selling Under Quality Uncertainty. Manufacturing \& Service Operations Management, pp. 1-16.

Schiefer, J. \& Fischer, C., 2008. The gap between wine expert ratings and consumer preferences: Measures, determinants and marketing implications. International Journal of Wine Business.

Stamp, C., 2015. The Economics of Wine Barrels: How to Determine the Effect of Barrel Choices on Profits. Wines and Vines, pp. 54-57.

Wine Institute Statistics, 2015. Table 1: World Wine Production by Country 2013-2015 and \% Change. Accessed on June 30, 2017 at:

http://www.wineinstitute.org/files/World_Wine_Production_by_Country_2015.pdf 